Hydrology and Earth System Sciences, 5(1), 75-81 (2001) @ C EGS

\title{
Evaluation of regional acid sensitivity predictions using field data: issues of scale and heterogeneity
}

\author{
B. Reynolds ${ }^{1 *}$, C. Neal ${ }^{2}$ and D.A. Norris ${ }^{1}$ \\ ${ }^{1}$ CEH, Bangor Research Unit, UWB, Deiniol Road, Bangor, Gwynedd, LL57 2UP, UK \\ ${ }^{2} \mathrm{CEH}$ Wallingford, Crowmarsh Gifford, Wallingford, OX10 8BB, UK \\ *e-mail for corresponding author: br@ceh.ac.uk
}

\begin{abstract}
An acid waters sensitivity map has been widely used as a background resource for assessing potential impacts of forest management on stream water acidity within Wales. The validity of this approach has been explored by comparing predicted acid sensitivity with the observed acid neutralisation capacity (ANC) in stream runoff using data sets from two regional surveys of a major area of acidification concern in Wales. For catchments in excess of 20 ha, the acid sensitivity predictions are generally upheld, although biologically important extremes of acidity are not predicted. For smaller catchments of 2 to 5 ha area, the large observed variations in ANC are poorly predicted from the acid sensitivity map; there is no statistically significant relationship between predicted sensitivity and measured baseflow and stormflow ANC values for the catchments. This reflects the high degree of heterogeneity within catchments and the complexity of soil and groundwater interactions. The maps offer a starting point for assessing sensitivity. However, they provide no more than a very crude indication at the scale of interest to forestry managers. It is concluded that a more appropriate route for assessing sensitivity is via field measurement and the direct use of water quality and biological information.
\end{abstract}

Keywords: streams, forestry, acidification, acid sensitivity mapping, ANC, Wales

\section{Introduction}

Surface water acidification remains a central issue of environmental concern for acidic and acid-sensitive areas in Britain in relation to both the atmospheric deposition of acidic pollutants and land use change (UKAWRG, 1988; Monteith and Evans, 2000). Thus, there is a fundamental need in environmental planning for the provision of a regional representation of areas of critical concern. One approach has been to use maps to predict the acid sensitivity of freshwaters from regional geology, soil and land use characteristics, often at a resolution of one $\mathrm{km}^{2}$ (Hornung et al., 1995). However, water quality variability occurs at a much finer scale (Hill and Neal, 1997) and practical management issues often relate to catchments that are orders of magnitude smaller in area, thus risking a potential mismatch between the regional data and the specific requirements for local environmental risk assessment. There is an additional danger that "broad brush" regional approaches become the accepted "ground truth" of how environmental systems actually function with an understatement of the scientific uncertainty in the models and the extent of variability within catchment systems (Neal, 1997).

As part of a recent study of the water quality effects of forest harvesting and replanting in the British uplands, the issues of matching scientific understanding from detailed site studies to the practical needs of water quality managers has been examined (Neal and Reynolds, 1998). A nested series of studies was undertaken to characterise spatial and temporal variability which extended to include other regional water quality studies. This provided a data set for testing predictions from regional mapping of acid sensitivity against observations of stream acidity across a range of catchment scales. The results of this comparison are presented to show that much more emphasis is required on measurement and assessment of extremes at the scale of concern to the local environmental manager. In doing so, the important issues of scale and heterogeneity are brought to the fore. 


\section{Background to Surface Water Acid Sensitivity M apping in G reat Britain}

Within Great Britain, the first map produced for the regional assessment of the acid sensitivity of freshwaters allocated map units on the $1: 65000$ geological map to one of four classes based on the geochemistry and mineralogy of the dominant rock types (Kinniburgh and Edmunds, 1986). It was recognised, however, that this map had short comings for the prediction of surface water acidity, in that whilst geology has an important influence on baseflow chemistry, soils are one of the main factors determining streamwater chemistry at high flows. Thus a new map was produced for
Great Britain (GB) which combined $1 \mathrm{~km}$ square databases of soil information with the geological data (Hornung et al., 1995). In the map, soil mapping units were assigned to one of three acid sensitivity classes according to data for base saturation and soil $\mathrm{pH}$. An overlay procedure within a Geographic Information System (GIS) was used to combine the resulting sensitivity map of the dominant soil within each $1 \mathrm{~km}$ square with a modified version of the Kinniburgh and Edmunds geology map to produce a combined map with five acid sensitivity classes (Fig. 1 and Table 1). In Wales, a simplified version of the GB map was produced by the National Rivers Authority (NRA), now part of the Environment Agency of England and Wales, for screening

\section{Sensitivity Classification}

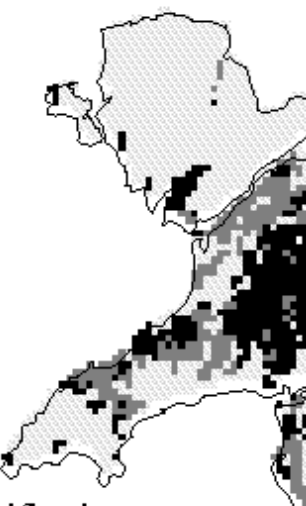

Non-Sensitive (Class1)

Low (Class 2)

Medium -Low (Class 3)

Medium -High (Class 4)

High (Class 5)

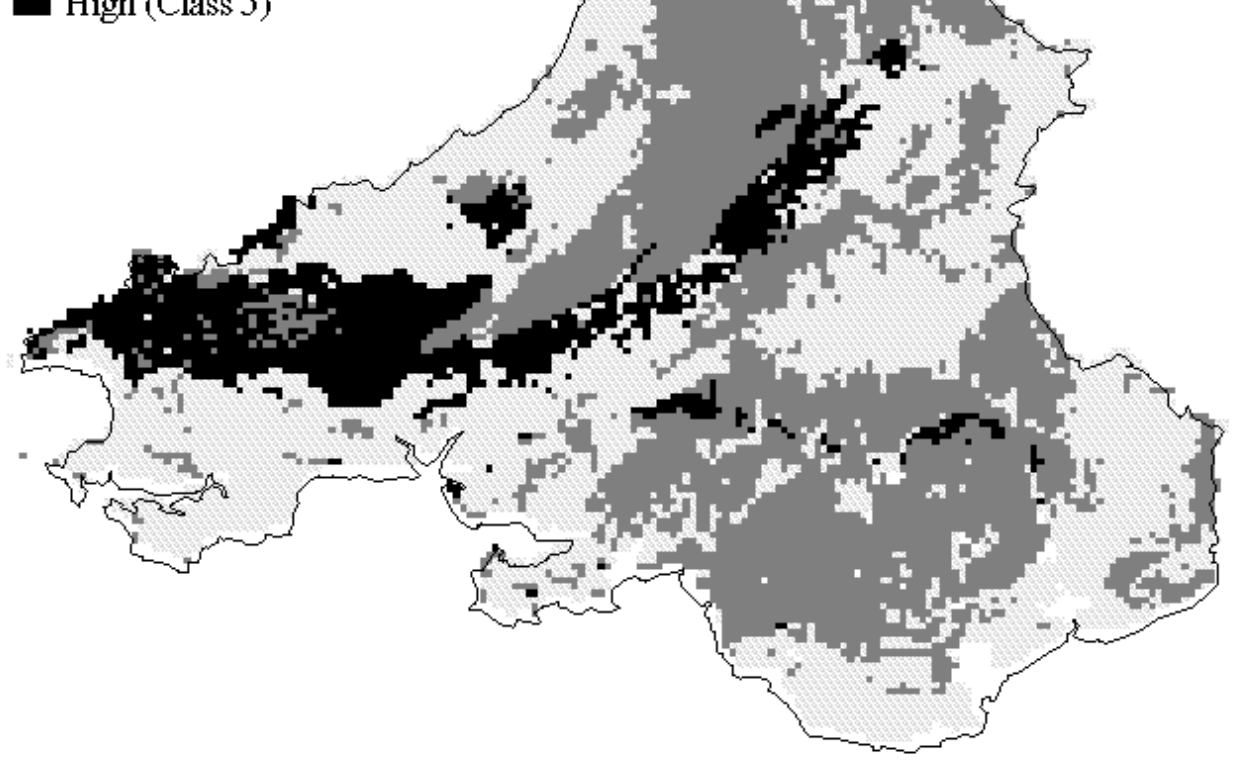

Fig. 1. Map of Wales showing the five band acid sensitivity classification of Hornung et al. (1995). 
Table 1. Surface water sensitivity classes for the Acid Waters Sensitivity Map of Great Britain (Hornung et al., 1995)

\begin{tabular}{lll}
\hline $\begin{array}{l}\text { Sensitivity } \\
\text { class }\end{array}$ & $\begin{array}{l}\text { Description } \\
\text { (sensitivity) }\end{array}$ & Prediction \\
\hline 1 & Non-sensitive & $\begin{array}{l}\text { Acidic waters will not occur } \\
\text { Acid waters very unlikely }\end{array}$ \\
2 & Low & Acid waters unlikely \\
3 & Medium-low \\
4 & Medium-high & $\begin{array}{l}\text { Acid waters likely at very } \\
\text { high flows } \\
\text { Acid waters will occur at all } \\
\text { flows }\end{array}$ \\
5 & High &
\end{tabular}

new forest planting applications where surface water acidification and the scavenging of acid atmospheric pollution by conifer canopies are the key issues. The modified Welsh map (Fig. 2) has two classes: non-sensitive (combination of GB map classes 1-3) and sensitive (combination of GB map classes 4 and 5).

The purpose of the acid waters sensitivity map was to predict average sensitivity at a resolution of 1 kilometre square. However, there has also been a water resource management requirement to use the maps at a finer scale to assess acidification and land-use change impacts, such as forest clearfelling and replanting in small, sensitive headwater catchments. This paper examines the potential for

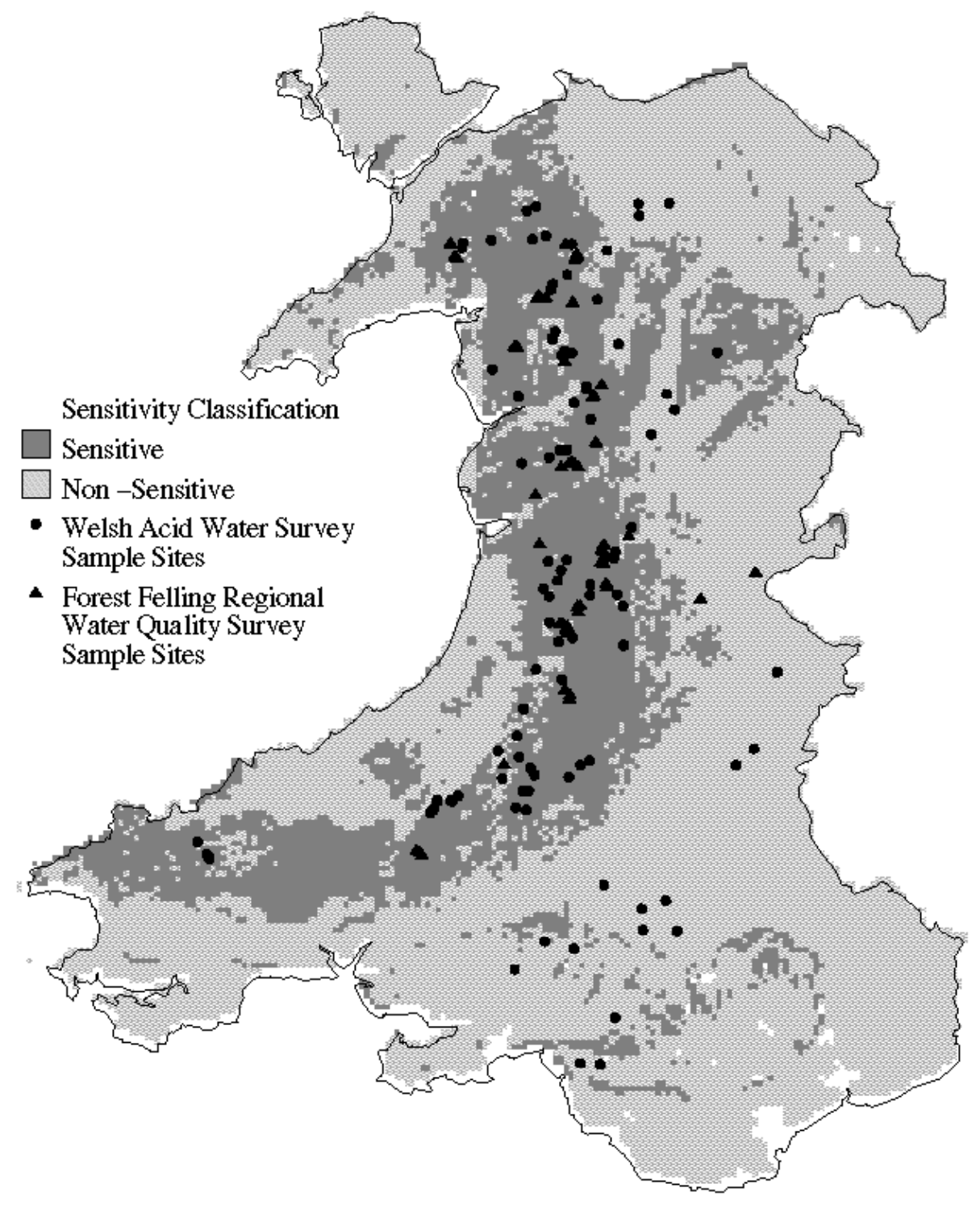

Fig. 2. Map of Wales showing the modified two band acid sensitivity classification and the location of sample sites for the Welsh Acid Waters Survey and the Forest Felling Regional Water Quality Survey. 
using the maps as a background resource for addressing this type of concern. To do so, the predicted acid sensitivity from the map is compared with the observed acid neutralisation capacity (ANC) in stream runoff using data sets from the Welsh Acid Waters Survey (WAWS; Stevens et al., 1997) and a Forest Felling Regional Water Quality Survey (FFRWQS; Neal et al., 1998).

\section{Survey data sets}

\section{THE WELSH ACID WATERS SURVEY}

The WAWS was undertaken between October 1994 and September 1995. It involved monthly sampling of stream water for one year at 102 upland catchments located in the acid sensitive parts of Wales as defined by the UK surface water acid sensitivity map. The catchments studied varied from 20 to 5673 ha in area and covered the range of acid upland soils and land use types encountered in Wales such as semi-natural acid grassland, acid wet heath and plantation conifer forest. For each catchment, a range of physical attributes was captured using digital data held on a GIS. With the exception of samples collected for $\mathrm{pH}$, alkalinity and conductivity determination, streamwater samples were filtered in the field into appropriate glass and plastic bottles and analysed for a range of major and minor solutes using standard methods at the Environment Agency's Llanelli laboratory (Stevens et al., 1997). Due to analytical uncertainties surrounding the alkalinity data, the ANC of samples was determined according to the charge balance $\left(\mathrm{ANC}_{\mathrm{cb}}\right)$ definition of Reuss et al. (1986) as:

$$
\begin{array}{r}
\mathrm{ANC}_{\mathrm{cb}}=\mathrm{S} \text { [strong base cations] - } \\
\mathrm{S} \text { [strong acid anions] }
\end{array}
$$

For this equation, the strong base cations are taken as sodium, potassium, calcium and magnesium, the strong acid anions as chloride, sulphate and nitrate, while the square brackets, [], refer to concentrations in $\mathrm{mEq}^{-1}$.

\section{FOREST FELLING REGIONAL WATER QUALITY}

\section{SURVEY}

The rationale behind this sampling programme was to obtain soil/hillslope drainage "endmember" chemistries representative of a variety of soil types in order to describe how the chemical composition of the major inputs to streamflow generation change with forest clearfelling. Sixtyseven first-order stream catchments of 2 to 5 ha area were chosen to provide a comparison between 16 sites with standing crops of first rotation, mature Sitka spruce (Picea sitchensis) and the remainder where the forest had been clear- felled from less that one up to 40 years previously. Water samples were collected at both baseflow and highflow extremes using a campaign approach (Neal et al., 1998). Seasonality was incorporated by sampling autumn, winter and spring stormflow periods and spring, summer, autumn and winter baseflow periods. The campaigns covered the period autumn 1995 to spring 1998. Samples were collected in appropriate cleaned glass and plastic bottles and filtered in the laboratory within two days through $0.45 \mathrm{~mm}$ membranes. Alkalinity by Gran titration and $\mathrm{pH}$ were determined on unfiltered samples. The ANC of individual samples was calculated from Gran alkalinity, total dissolved aluminium (T-Al) and dissolved organic carbon (DOC) concentrations using the methodology proposed by Neal et al. (1999)

$$
\mathrm{ANC}=[\mathrm{G}-\mathrm{Alk}]-3 *\{\mathrm{~T}-\mathrm{Al}\}+0.054 *\{\mathrm{DOC}\}
$$

In this equation, [] and \{\} refer to concentrations in $\mathrm{mEq}^{-1}$, as above, and $\mathrm{mM} \mathrm{l}^{-1}$ units respectively. DOC and T-AL were determined on filtered samples at CEH Wallingford using standard techniques (Neal et al., 1992). The two methods of ANC determination are considered to give comparable results (Neal et al., 1999).

\section{DETERMINATION OF CATCHMENT ACID SEN SITIVITY}

To increase the resolution of the acid sensitivity mapping, the soil and geology data for each of the WAWS catchments was remapped into (a) the five acid sensitivity classes used in the original GB map (Hornung et al., 1995) and (b) the sensitive and non-sensitive classes used in the Welsh NRA map. Three statistics were used to obtain a single sensitivity value for each catchment, (1) an area weighted value, (2) the modal value (i.e. the single class occupying the largest area in the catchment) and (3) the value at the sampling point. As no digital catchment data were available, the FFRWQS sites were classified as either sensitive or non-sensitive using the Welsh NRA map overlaid with the locations of the sample points.

\section{Results and discussion}

\section{THE WELSH ACID WATERS SURVEY CATCHMENTS}

Relationships between water chemistry and catchment sensitivity class are investigated using the annual mean, minimum and maximum $\mathrm{ANC}_{\mathrm{cb}}$ values for each catchment. The minimum value is assumed to represent storm flow conditions when acidic runoff from the catchment increasingly dominates streamflow and chemical conditions are least favourable for stream biota. Low flow chemistry is 
a)

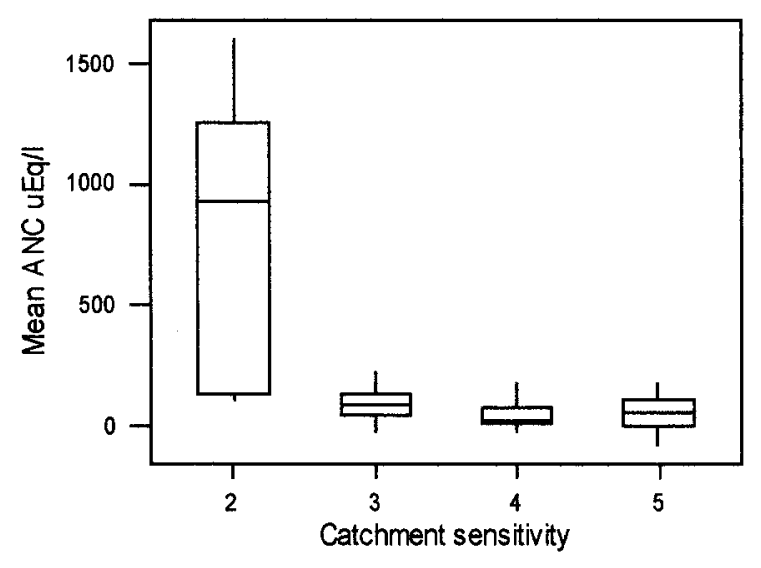

b)

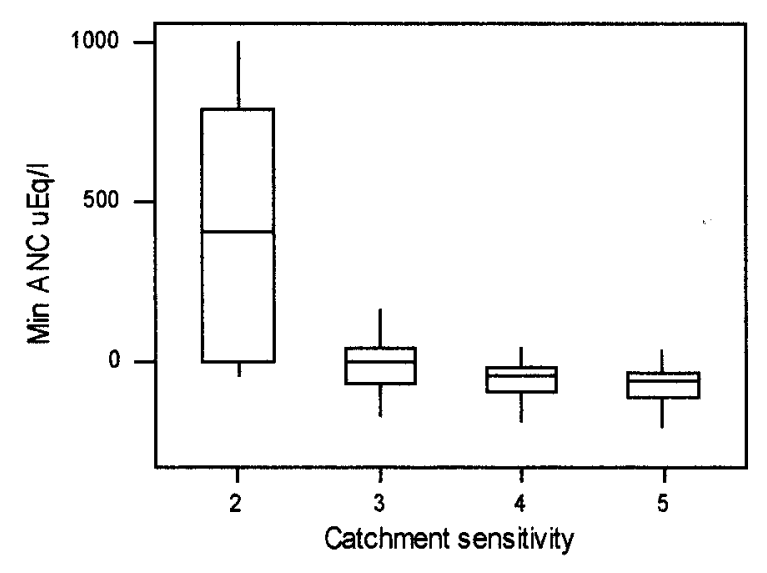

c)

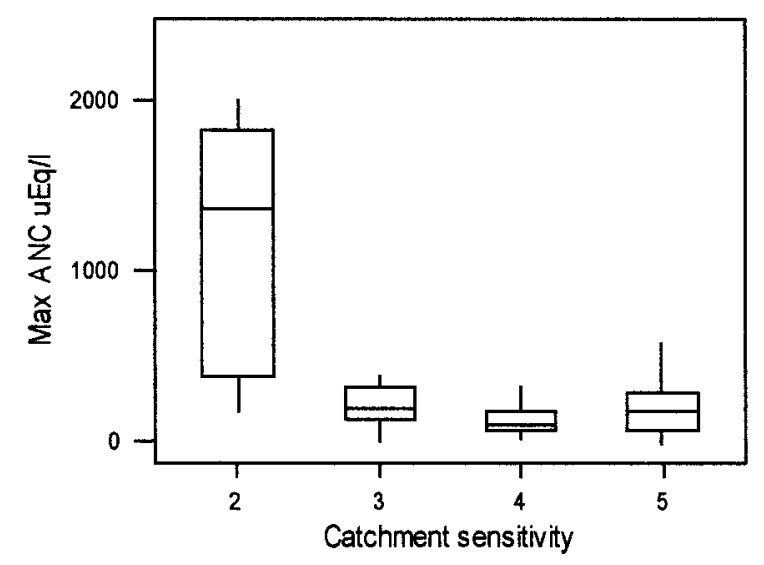

Fig. 3. Box and Whisker plots summarising the distribution of (a) mean, (b) minimum and (c) maximum $A N C_{c b}$ concentrations for the Welsh Acid Waters Survey catchments with respect to the five band acid sensitivity classification. Line across box represents the median value, upper and lower box boundaries are first and third quartile values.
Table 2. Summary of the mean, minimum and maximum values of $\mathrm{ANC}_{\mathrm{cb}}\left(\mathrm{mEq} \mathrm{l}^{-1}\right)$ observed in twelve monthly samples from 102 WAWS catchments classified according to catchment area weighted acid sensitivity using the simplified two band approach

\begin{tabular}{llrrrrr}
\hline $\begin{array}{l}\text { ANC } \\
\text { value }\end{array}$ & Sensitivity & Mean se. & Min & Max & $N$ \\
\hline Mean & Non-sensitive & 289 & 67 & -22 & 1592 & 39 \\
& Sensitive & 77 & 17 & -3 & 910 & 63 \\
& & & & & & \\
\multirow{2}{*}{ Min } & Non-sensitive & 95 & 43 & -171 & 996 & 39 \\
& Sensitive & -62 & 11 & -270 & 217 & 63 \\
& & & & & & \\
Max & Non-sensitive & 528 & 101 & 8 & 2354 & 39 \\
& Sensitive & 212 & 38 & -1 & 1794 & 63 \\
& & & & & & \\
\hline
\end{tabular}

represented by the maximum $\mathrm{ANC}_{\mathrm{cb}}$ when stream flow is dominated by longer residence time water originating from depth in the soil profile or from shallow groundwater. Statistical analysis of these data shows that the relationship between stream water $\mathrm{ANC}_{\mathrm{cb}}$ and the acid sensitivity of the catchment does not depend ( $p>0.15,1$-Way Analysis of Variance (ANOVA)) on how the acid sensitivity class is assigned to the catchment. To simplify matters, only the catchment area-weighted sensitivity data are presented in Fig. 3 and Tables 2 and 3.

One-way ANOVA of the WAWS data in relation to the original five band classification of acid sensitivity, shows that there are no significant differences in mean and maximum $\mathrm{ANC}_{\mathrm{cb}}$ between classes 3, 4 and 5 ( $p>0.5$ and $p$ $>0.10$ respectively; Fig. 3). However, there are significant differences between minimum $\mathrm{ANC}_{\mathrm{cb}}$ values $(p<0.01)$ with sites in classes 4 and 5 having large negative ANC values (59 and $-67 \mathrm{mEq} \mathrm{1}^{-1}$ respectively). Sites in the second class have water chemistries significantly less acidic $(p<0.001)$ than any of the other classes. There are no WAWS sites in class 1 .

For the simplified classification, the $\mathrm{ANC}_{\mathrm{cb}}$ data show that stream water is significantly less acid $(p<0.001)$ in the nonsensitive catchments (Table 2). However, catchments classified as non-sensitive can still have a minimum $\mathrm{ANC}_{\mathrm{cb}}$ value considerably below zero - the value commonly used to indicate acidity levels harmful to aquatic biota (CLAG, 1995). Indeed, $46 \%$ of non-sensitive catchments mapped according to catchment area weighting had minimum $\mathrm{ANC}_{\mathrm{cb}}$ values less than zero with $54 \%$ having a value less than $20 \mathrm{mEq} \mathrm{l}^{-1} ; 92 \%$ of the sensitive catchments had $\mathrm{ANC}_{\mathrm{cb}}$ minima less than zero. Only one non-sensitive and one 
Table 3. Mean, minimum and maximum ANC $\left(\mathrm{mEq}^{-1}\right)$ values observed in the FFRWQS streams classified according to the acid sensitivity of the catchment sampling point for (a) all data and (b) samples with $\mathrm{NO}_{3}$ concentrations less than $3 \mathrm{mg} \mathrm{l}^{-1}$

\begin{tabular}{llcrlll}
\hline (a) & Sensitivity & Mean ANC & se. & Min ANC & Max ANC & N \\
\hline \multirow{2}{*}{ Baseflow } & Non-sensitive & 18.0 & 23.5 & -120.9 & 464.7 & 26 \\
& Sensitive & -5.8 & 8.4 & -167.7 & 385.2 & 99 \\
Stormflow & Non-sensitive & 0.6 & 14.1 & -112.4 & 346.4 & 47 \\
& Sensitive & -16.6 & 5.4 & -123.8 & 349.8 & 173 \\
\hline (b) & Sensitivity & Mean ANC & se. & Min ANC & Max ANC & N \\
\hline \multirow{2}{*}{ Baseflow } & Non-sensitive & 26.9 & 24.1 & -50.0 & 464.7 & 20 \\
& Sensitive & 4.3 & 9.4 & -100.0 & 385.2 & 83 \\
Stormflow & Non-sensitive & 0.3 & 12.7 & -109.3 & 295.2 & 42 \\
& Sensitive & -10.8 & 6.5 & -104.5 & 349.8 & 137 \\
\hline
\end{tabular}

sensitive catchment had a maximum observed ANC less than $20 \mathrm{mEq} \mathrm{1}^{-1}$. The ANC value of $20 \mathrm{mEq} \mathrm{1}^{-1}$ has been used in Scandinavian countries as the critical chemical value for fish in surface waters (Henriksen et al., 1995).

The WAWS data show that whilst the acid sensitivity predictions are generally upheld for catchments in excess of 20 ha with a variety of land use types, biologically important extremes of acidity are not predicted.

\section{FOREST FELLING REGIONAL WATER QUALITY SURVEY}

The large variations in water quality observed in this data set are poorly predicted using the acid sensitivity map (Table 3). There is no statistically significant relationship between predicted acid sensitivity and either baseflow (maximum) or stormflow (minimum) ANC values ( $p>0.15,1$-Way ANOVA; Table 3a). This result becomes even stronger when those sites influenced by the post-felling nitrate pulse (nitrate concentrations greater than $\left.3 \mathrm{mg} \mathrm{l}^{-1}\right)$ are removed $(p>0.3$, 1-Way ANOVA; Table 3b). These sites are typically those which had been clear-felled between six months and two years prior to the water quality surveys. Some extremely acid waters were observed in the non-sensitive catchments even under baseflow conditions. Of the 26 baseflow samples from non-sensitive sites, eight had negative ANC values while a further 14 had ANC values less than $20 \mathrm{mEq} \mathrm{l}^{-1}$. Conversely, under stormflow conditions, some highly positive ANC values were observed in catchments classified as acid sensitive. The results show that the high degree of spatial heterogeneity in the hydrochemistry of small catchments cannot be predicted from relatively coarse scale regional mapping.

\section{Conclusions}

Clearly, the water quality of catchments is highly variable in both space and time. The temporal variability is associated with hydrological controls and has been well known for the past 20 or more years, but the magnitude of small scale spatial variability has only been recognised more recently. The acid sensitivity maps derive from this earlier period. The maps depend on the underlying assumption that streamwater chemistry varies in a predictable manner with respect to the geochemical properties of catchment soils and geology. This allows geochemically similar units to be lumped together to produce a simplified classification of anticipated stream hydrochemical response to temporal variations in hydrological conditions. The data described in this paper reveal a high degree of spatial variation in the hydrochemistry of streams derived from the same, apparently geochemically uniform soils and bedrock. This variation occurs both between and within catchments and across a wide range of spatial scales and could not have been anticipated when the acid sensitivity maps were originally constructed. The water quality data imply firstly that there is considerable and unmapped, fine scale variation in the geochemistry of rocks and soils which can have a marked affect on streamwater acidity and secondly that the interactions between acidic soil water and neutral to alkaline groundwater within catchments are complex. As a result, the maps cannot cope with water 
quality variability at the smaller scales which are often important for the purposes of practical water quality management. Furthermore, the maps do not pick up the variability in the chemically important extremes of acidity at a regional level - even at the catchment scales they were designed to describe. The conclusion is that while the maps offer a starting point for assessing sensitivity, they provide no more than a very crude indication. A more appropriate route for assessing the sensitivity of catchments is via field campaigns and direct measurement of water quality and biological data gathered for the purpose.

\section{Wider comment}

Over the past 20 years or so, there has been a growing perception that:

i. acidification processes are well understood;

ii. these processes can be reduced to a relatively simple set of key operators;

iii. the key operators can be combined with regional scale data to predict environmental conditions and responses at regional scales;

iv. the regional predictions are sufficient to determine environmental management policies.

Arising from this has been the rapid development and policy application of simple rule-based or steady-state models using regional environmental data bases mounted on a GIS such as described in this paper. These have been successful as tools for providing an effects-based approach (critical loads) to the reduction in the emission of acidifying pollutants at national and international scales. However the data presented here, which add to our published work, show that the true situation is far more complex. Thus, the highly heterogeneous nature of catchments confounds our understanding of the acidification processes and places constraints on our ability to predict the environmental consequences of changes in industrial emissions and land use. Uncertainty and scale are issues of major concern in relation to acid sensitivity mapping and critical loads which are not presently resolved (Lokke et al., 2000). However, the main point of this paper in relation to parallel studies is that the basis of environmental decision-making must still rest within the context of measurement to show what actually happens within a fractal world of emergent properties, climate instability and a changing economic base (Neal, 2000).

\section{Acknowledgements}

We would like to record our gratitude to Forest Enterprise staff, colleagues at CEH Wallingford, Plynlimon, CEH Bangor and the University of Wales, Cardiff, for valuable assistance with sample collection and analysis during the FFRWQS and the WAWS. The work was funded by the Environment Agency, the Welsh Office, the Countryside Council for Wales, the Forestry Commission and the NERC.

\section{References}

CLAG, 1995. Critical Loads of Acid Deposition for United Kingdom Freshwaters. Critical Loads Advisory Group, Sub-Group Report on Freshwaters, Institute of Terrestrial Ecology, Edinburgh.

Henriksen, A., Posch, M., Hultberg, H. and Lien, L., 1995. Critical loads of acidity for surface waters - Can the $\mathrm{ANC}_{\text {limit }}$ be considered variable? Wat. Air Soil Pollut., 85, 2419-2424.

Hill, T. and Neal, C., 1997. Spatial and temporal variation in $\mathrm{pH}$, alkalinity and conductivity in surface runoff and groundwater for the Upper River Severn catchment. Hydrol. Earth Syst. Sci., 1, 697-715.

Hornung, M., Bull, K.R., Cresser, M., Ullyet, J., Hall, J.R., Langan, S., Loveland, P.J. and Wilson, M.J., 1995. The sensitivity of surface waters of Great Britain to acidification predicted from catchment characteristics. Environ. Pollut., 87, 207-214.

Kinniburgh, D.G. and Edmunds, W.M., 1986. Maps of susceptibility of UK surface and groundwaters to acid deposition. In: Acidity in United Kingdom Fresh Waters. Interim Report UK Acid Waters Review Group, HMSO, London.

Lokke, H., Bak, J., Bobbink, R., Bull, K., Curtis, C., FalkengrenGrerup, U., Forsius, M., Gundersen, P., Hornung, M., Skjelkvale, B.L., Starr, M. and Tybirk, K., 2000. Critical Loads Copenhagen 1999. 21st-25th November 1999. Arbejdsrapport fra DMU nr 121, Ministry of Environment and Energy National Environment Research Institute, Silkeborg, Denmark, 48 pp.

Monteith, D.T. and Evans, C. (Eds.), 2000. UK Acid Waters Monitoring Network: 10 Year Report. ENSIS Publishing, London, 364 pp.

Neal, C., 1997. A view of water quality from the Plynlimon watershed. Hydrol. Earth Syst. Sci., 1, 743-753.

Neal, C., 2000. Catchment science in a heterogeneous world: reflections on the water quality functioning of the Plynlimon catchments, Plynlimon, mid-Wales. In: Water in the Celtic World: Managing Resources for the $21^{\text {st }}$ Century. (Eds. J.A.A. Jones, K. Gilman, A. Jigorel and J. Griffin). BHS Occasional Paper No. 11, 189-196.

Neal, C. and Reynolds, B., 1998. The Impact of Conifer Harvesting and Replanting on Upland Water Quality. $\mathrm{R}$ and $\mathrm{D}$ Technical Report P211, Environment Agency, Bristol.

Neal, C., Reynolds, B. and Robson, A.J. 1999. Acid neutralisation capacity measurements within natural waters: towards a standardised approach. Sci. Tot. Envir., 243/244, 233-241.

Neal, C., Fisher, R., Hill, S., Neal, M., Conway, T., Ryland, G.P. and Jeffrey, H.A., 1992. The effects of tree harvesting on stream water quality at an acidic and acid sensitive spruce forested area: Plynlimon, Mid-Wales. J. Hydrol., 135, 305-319.

Neal, C., Reynolds, B., Wilkinson, J., Hill, T., Neal, M., Hill, S. and Harrow, M., 1998. The impacts of conifer harvesting on runoff water quality: a regional survey for Wales. Hydrol. Earth Syst. Sci., 2, 323-344.

Reuss, J.O., Christophersen, N. and Seip, H.M., 1986. A critique of models for freshwater and soil acidification. Wat. Air Soil Pollut., 30, 909-931.

Stevens, P.A., Ormerod, S.J. and Reynolds, B., 1997. Final Report of the Acid Waters Survey for Wales. Volume 1, Main Text. Centre for Ecology and Hydrology, Bangor.

UKAWRG, 1988. Acidity in United Kingdom Fresh Waters. United Kingdom Acid Waters Review Group Second Report, Her Majesty's Stationery Office, London. 